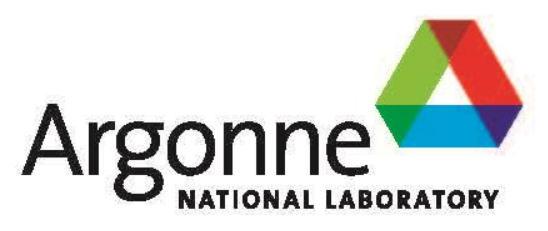

ANL/NE-15/1

\title{
Evaluation of an Alternative Method for Beam Window Temperature Monitoring
}

Nuclear Engineering Division 


\begin{abstract}
About Argonne National Laboratory
Argonne is a U.S. Department of Energy laboratory managed by UChicago Argonne, LLC under contract DE-AC02-06CH11357. The Laboratory's main facility is outside Chicago, at 9700 South Cass Avenue, Argonne, Illinois 60439. For information about Argonne and its pioneering science and technology programs, see www.anl.gov.
\end{abstract}

\title{
DOCUMENT AVAILABILITY
}

Online Access: U.S. Department of Energy (DOE) reports produced after 1991 and a growing number of pre-1991 documents are available free via DOE's SciTech Connect (http://www.osti.gov/scitech/).

Reports not in digital format may be purchased by the public from the National Technical Information Service (NTIS):

U.S. Department of Commerce

National Technical Information Service

5301 Shawnee Road

Alexandria, VA 22312

unw.ntis.gov

Phone: (800) 553-NTIS (6847) or (703) 605-6000

Fax: (703) 605-6900

Email: orders@ntis.gov

Reports not in digital format are available to DOE and DOE contractors from the Office of Scientific and Technical Information (OST):

U.S. Department of Energy

Office of Scientific and Technical Information

P.O. Box 62

Oak Ridge, TN 37831-0062

unw.osti.gov

Phone: (865) 576-8401

Fax: (865) 576-5728

Email: reports@osti.gov

\section{Disclaimer}

This report was prepared as an account of work sponsored by an agency of the United States Government. Neither the United States Government nor any agency thereof, nor UChicago Argonne, LLC, nor any of their employees or officers, makes any warranty, express or implied, or assumes any legal liability or responsibility for the accuracy, completeness, or usefulness of any information, apparatus, product, or process disclosed, or represents that its use would not infringe privately owned rights. Reference herein to any specific commercial product, process, or service by trade name, trademark, manufacturer, or otherwise, does not necessarily constitute or imply its endorsement, recommendation, or favoring by the United States Government or any agency thereof. The views and opinions of document authors expressed herein do not necessarily state or reflect those of the United States Government or any agency thereof, Argonne National Laboratory, or UChicago Argonne, LLC. 


\section{Evaluation of an Alternative Method for Beam Window Temperature Monitoring}

by

Sergey Chemerisov

Nuclear Engineering Division, Argonne National Laboratory

prepared for

U.S. Department of Energy, National Nuclear Security Administration,

Office of Defense Nuclear Nonproliferation

October 2014 



\section{CONTENTS}

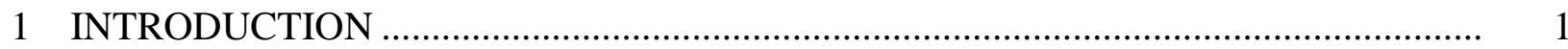

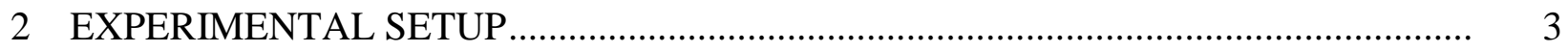

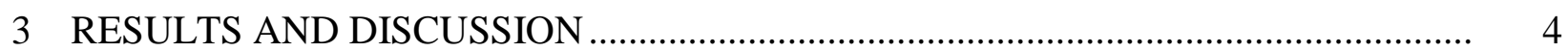

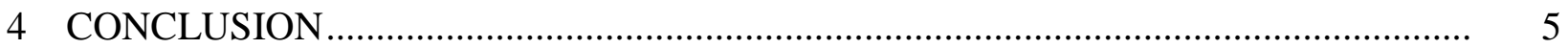

\section{FIGURES}

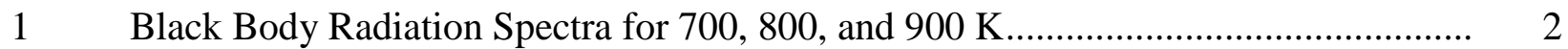

2 Experimental Setup for Spectrophotometric Temperature Monitoring ..................... 3

3 Emission Spectra of the Stainless Steel Sample Recorded at Temperatures from

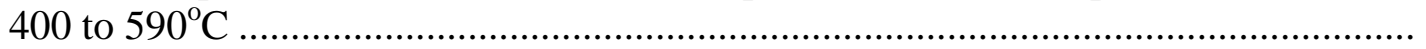

$4 \quad$ Black Body Radiation Spectra at 700-900 K Superimposed on Sensitivity Ranges of $\mathrm{Si}, \mathrm{InGaAs}$, and $\mathrm{PbSe}$ Detectors 
This page intentionally left blank 


\section{EVALUATION OF AN ALTERNATIVE METHOD FOR BEAM WINDOW TEMPERATURE MONITORING}

\section{INTRODUCTION}

A molybdenum-99 production system utilizing a Linac electron source beam and the $\gamma / \mathrm{n}$ reaction on Mo-100 metal targets will employ cooling with high-pressure helium $(\mathrm{He})$ gas. The electron beam will go through a window that separates the high-pressure He gas and the vacuum of the accelerator beam line. Electrons penetrating the window will generate significant heat deposition (heating) in the window; also, the window will be under mechanical stress due to the pressure differential and the cooling from one side only. These factors make the beam window the most critical element of the target. To prevent window failure, the temperature must be maintained below $800^{\circ} \mathrm{C}$. To monitor temperature during irradiation in ongoing experiments, we are using an infrared (IR) camera. Our operational experience with those cameras during previous irradiations showed that cameras are sensitive to the radiation; cameras often failed during irradiation experiments and prevented us from completing all planned activities. In a production facility, the cameras will be heavily shielded, but, even with this heavy shielding, they will have a finite lifetime. Testing of the radiation stability of the IR cameras is in progress. In the first part of the study, we completed irradiation with up to $3 \mathrm{MeV}$ x-rays from a Van de Graaff accelerator, and irradiations with neutrons and combination of high energy $\mathrm{x}$-rays and neutrons will continue in 2015 . Because IR cameras are quite expensive $(\sim 20 \mathrm{k})$ and so critical for operations, we decided to look at an alternative method of measuring the temperature of the beam window.

The alternative we studied to measure the temperature is the use of a spectrophotometer for visible to near infrared light. The basis for this study is that any physical body at given temperature T emits light according to Planck's law:

$$
I(v, T)=\frac{2 h v^{3}}{c^{2}} \frac{1}{e^{\frac{h v}{k T}}-1}
$$

where $I(v, T)$ is the energy per unit time radiated per unit area of the emitting surface in the normal direction per unit solid angle per unit frequency by a black body at temperature $T$;

$h$ is the Planck constant;

$c$ is the speed of light in a vacuum;

$k$ is the Boltzmann constant;

$v$ is the frequency of the electromagnetic radiation; and

$T$ is the absolute temperature of the body.

Calculated black body spectra for 700, 800, and $900 \mathrm{~K}$ are shown in Figure 1. In the $600 \mathrm{~nm}$ to $1100 \mathrm{~nm}$ spectral range, light intensity changes by three orders of magnitude. This spectral range is very attractive for precise temperature measurements. 


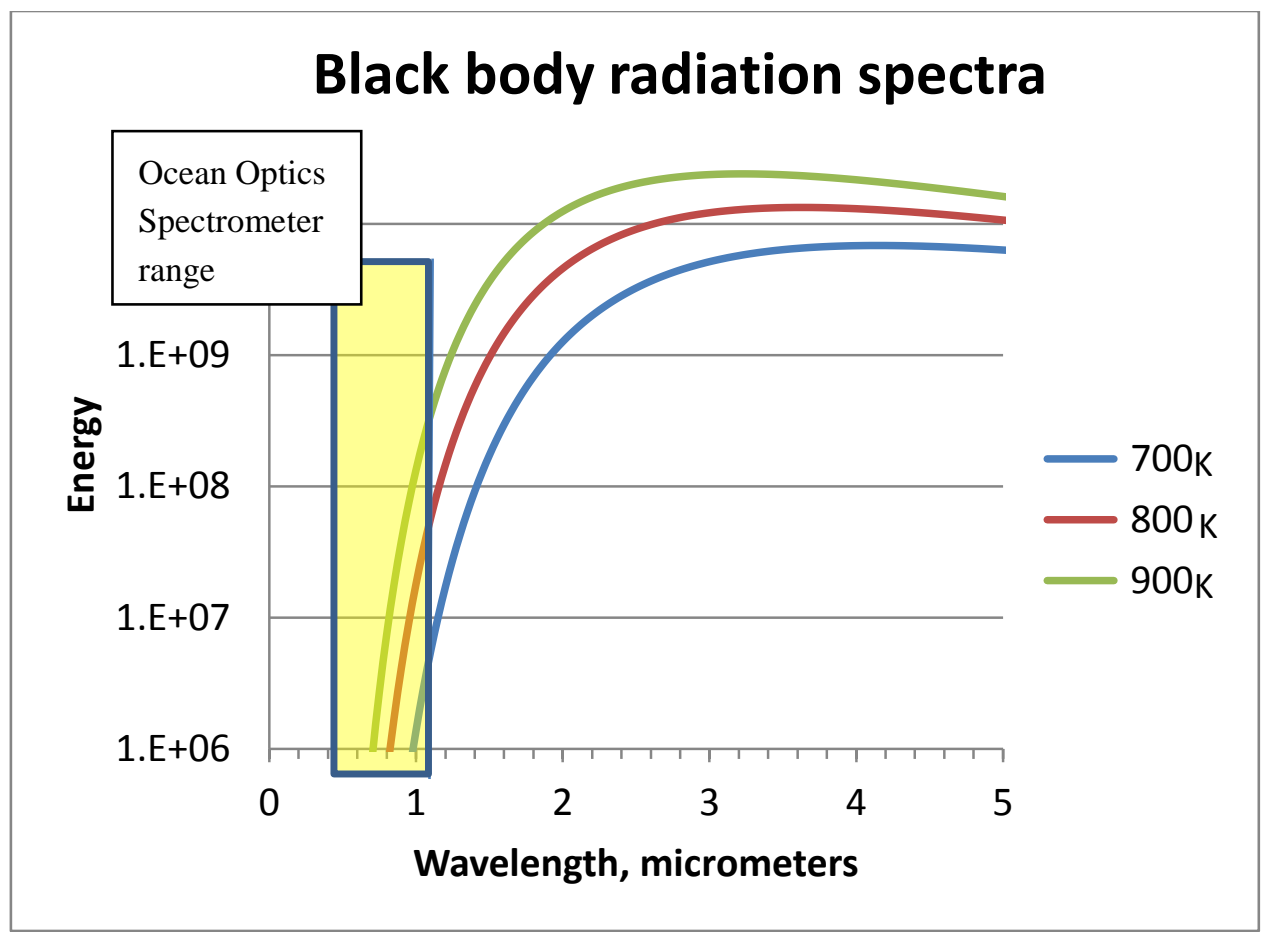

FIGURE 1 Black Body Radiation Spectra for 700, 800, and $900 \mathrm{~K}$ 


\section{EXPERIMENTAL SETUP}

To test our approach, we built the experimental setup shown in Figure 2. This setup consists of a vacuum chamber housing ( 1.5 in $x 1$ in. $x 0.5$ in. piece of stainless steel with two heater elements). Temperature of the sample is controlled by changing the power supplied by a variable-voltage transformer. Two type-K thermocouples are used to monitor the temperature of the sample. One is mounted on top of the sample, and the other is attached to the back of the sample. During the measurements, temperature differences between these thermocouples did not exceed $10 \mathrm{~K}$. The vacuum chamber is equipped with a quartz window to observe the sample and measure light emitted by the hot object. A turbo-pump-based vacuum system attached to the chamber allows evacuation of the chamber to $10^{-7}$ mbar.

The light detection system consists of an off-axes parabolic coupler for the light fiber, the fiber, and the spectrophotometer. The choice of the off-axes parabolic fiber coupler was dictated by the desire to avoid wavelength dependence of the coupling efficiency. The fiber was chosen to provide good light transmission in the range of $500-1200 \mathrm{~nm}$.

We used an Ocean Optics SP2000 spectrophotometer. The spectral range for this silicondetector-based spectrometer is $500-1100 \mathrm{~nm}$. This spectrometer is inexpensive, compact, and easy to use.

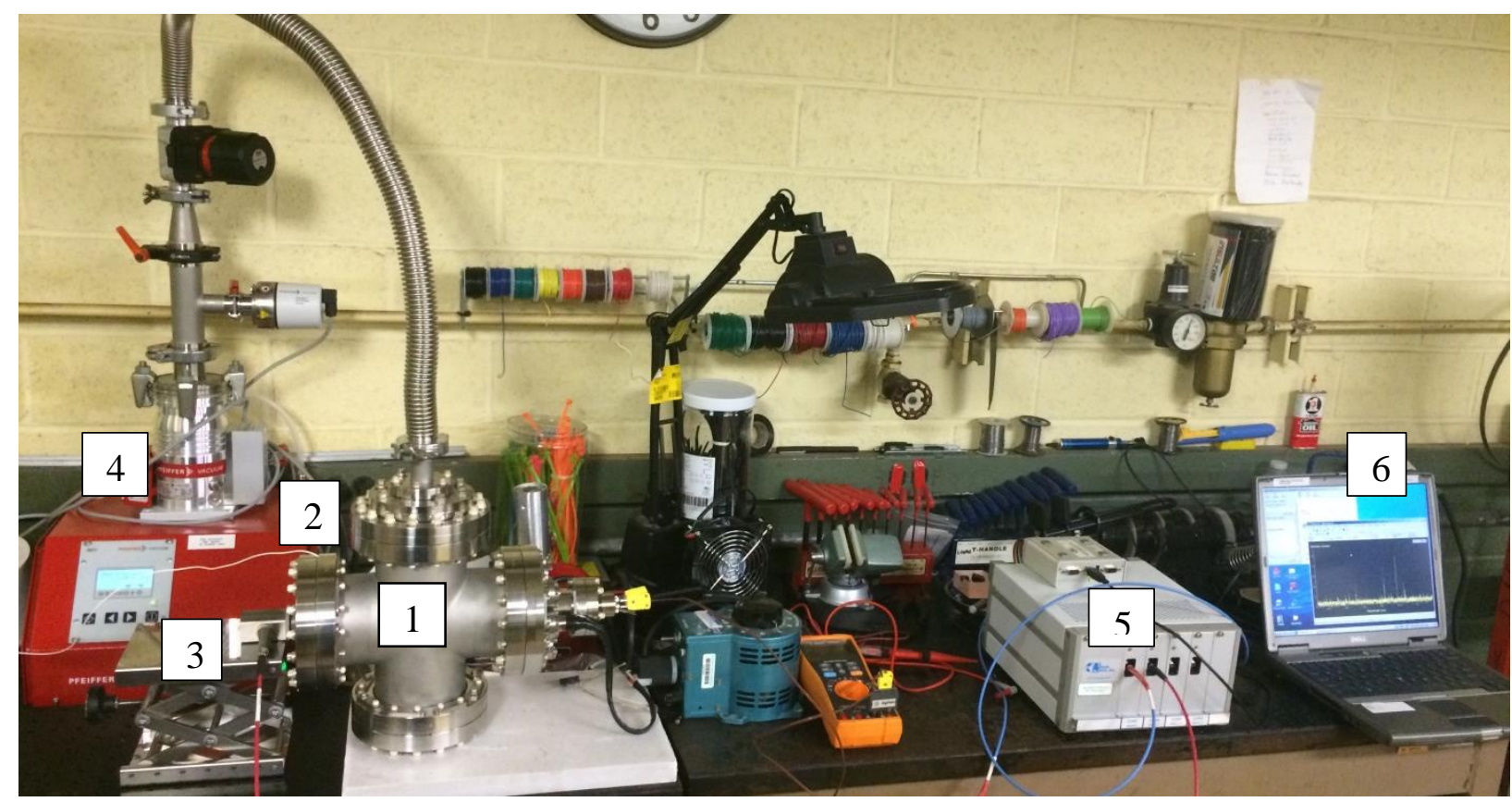

1. Vacuum chamber

2. Quartz window
3. Parabolic coupler

4. Pumping station
5. Spectrophotometer

6. Data-acquisition computer

FIGURE 2 Experimental Setup for Spectrophotometric Temperature Monitoring 


\section{RESULTS AND DISCUSSION}

The stainless-steel sample was heated to $600^{\circ} \mathrm{C}$. At this temperature, the sample was glowing a dark red, which was visible in the low light conditions. Then, the heaters were turned off and the sample was slowly cooling down. We took spectrophotometer measurements during cool down to avoid any contamination of the spectrum by light coming directly from heater elements. The resulting spectra are depicted in Figure 3. These spectra are the result of the convolution of sample emission spectra and spectrophotometer response.

As one can see, the spectra differ significantly between 500 and $590^{\circ} \mathrm{C}$. This finding suggests that it should be possible to detect changes in temperature within $5^{\circ} \mathrm{C}$ by using the integrated intensities. Also, detection at different wavelengths can allow compensation for changes in emissivity of the sample or transmission efficiency of the window or the mirror.

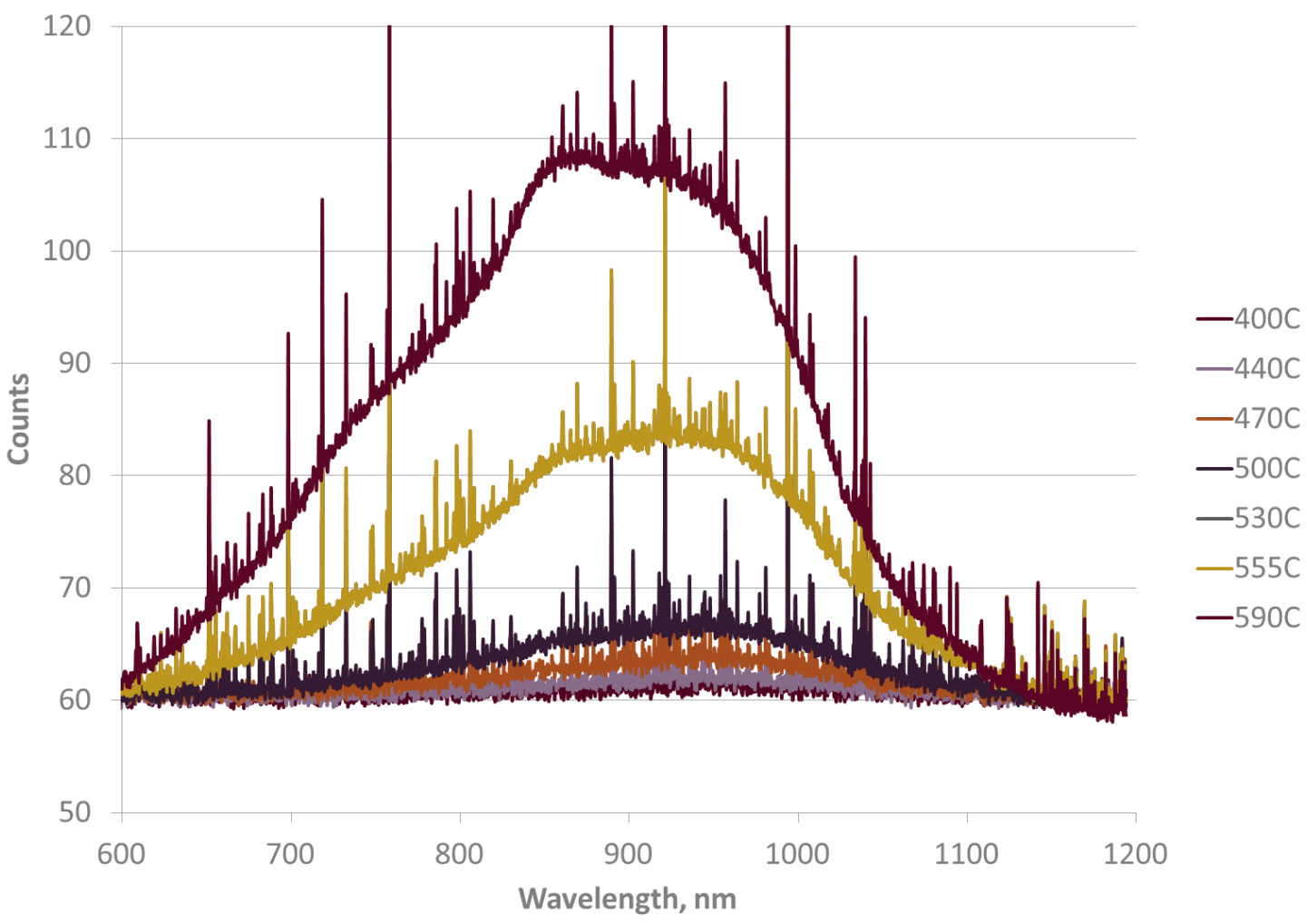

FIGURE 3 Emission Spectra of the Stainless Steel Sample Recorded at Temperatures from 400 to $590^{\circ} \mathrm{C}$. Distance between Sample and Fiber coupler is $60 \mathrm{~cm}$ 


\section{CONCLUSION}

Use of the fiber spectrophotometer for temperature measurements seems to be a promising alternative to IR cameras. To develop this technique, significant effort needs to be dedicated to improve the software for fast spectral analysis as well as optimize the parameters of the spectrometer.

While, in this study, we used a spectrometer with silicon detector working in the 200-1100 nm range, one can use a spectrometer with an InGaAs detector that has sensitivity in the $900-2500 \mathrm{~nm}$ range or a PbSe detector that has sensitivity in the $1300-4800 \mathrm{~nm}$ range. Detection at longer wavelengths will improve the sensitivity of the detection (Figure 4). There are several commercial products available that can be utilized for temperature measurements with minimum modifications and development, and we would like to evaluate them for the target window temperature monitoring.

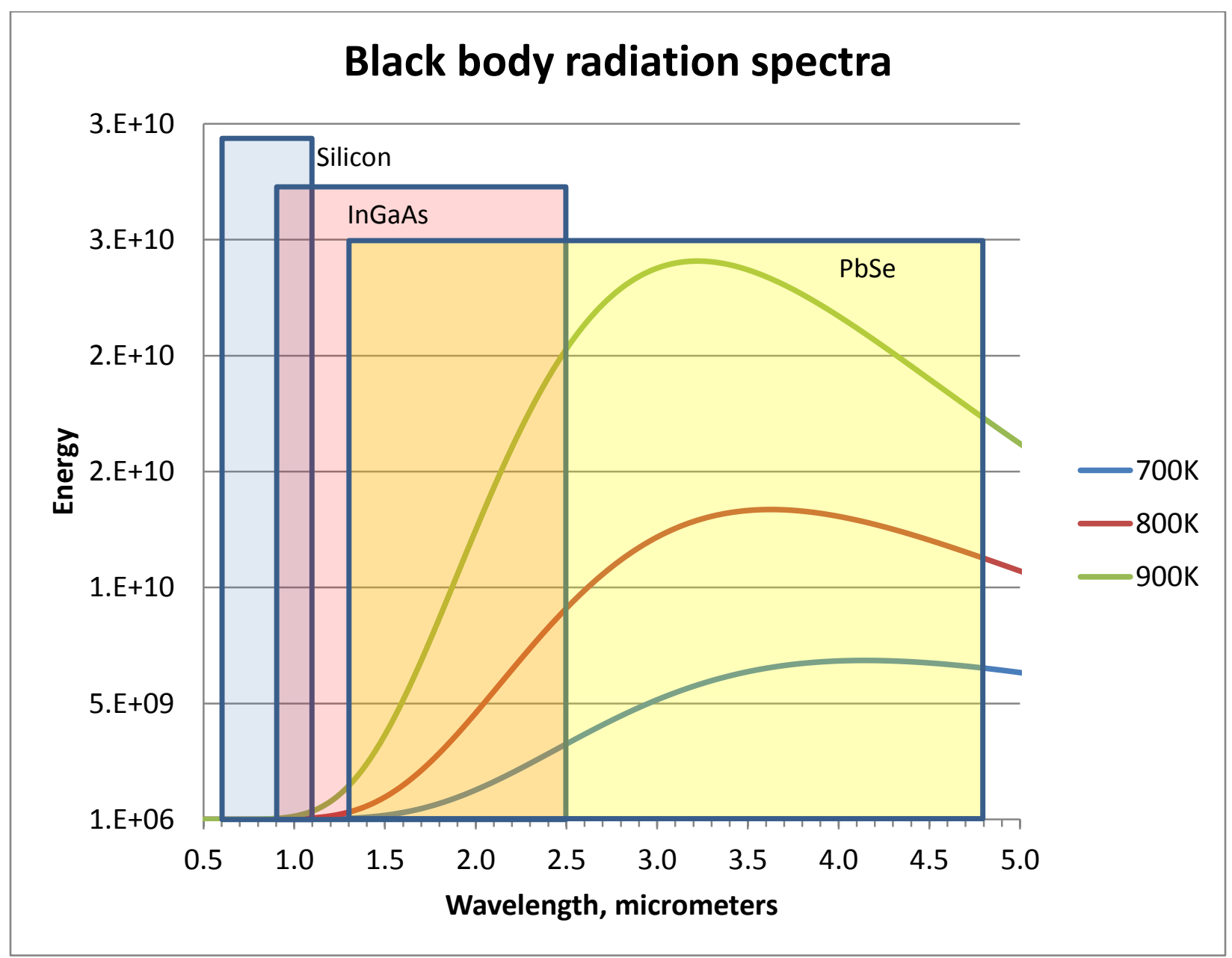

FIGURE 4 Black Body Radiation Spectra at 700-900 K Superimposed on Sensitivity Ranges of Si, InGaAs, and PbSe Detectors 
One of the great advantages of the IR camera is that it provides spatial distribution of the temperatures of the window. This is very hard to implement with a spectrometer-based approach. On the other hand, a fiber-optics-based spectrometer provides better flexibility because it can be placed far away from the target and can be well shielded.

Our initial testing of the setup for monitoring of the target window temperature showed that fiber-optics-based spectrometry is sensitive enough to detect the temperature of the target window. Utilization of the 600 to $1100 \mathrm{~nm}$ band provides high contrast for temperatures of interest $(700$ to $900 \mathrm{~K})$. While this method needs additional development, we are confident it can be employed for temperature monitoring. Use of an IR camera would be the preferred method for temperature monitoring due to its spatial resolution, but it can be replaced with the spectrometer alternative if the radiation sensitivity of the camera will be problematic in the Mo-99 production facility. 



\section{Argonne}

\section{Nuclear Engineering Division}

Argonne National Laboratory

9700 South Cass Avenue, Bldg. 205

Argonne, IL 60439-5484

www.anl.gov

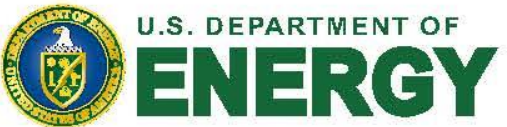

Argonne National Laboratory is a U.S. Department of Energy

laboratory managed by UChicago Argonne, LLC 